\title{
Research on the Characteristics of Modern Environmental Ceramics
}

\author{
Jun Chen ${ }^{1,2}$, Bingqin $\mathrm{He}^{1}$ and Zhang Rui ${ }^{2}$ \\ 1. Graduate School of Jingdezhen Ceramic University, 333403 \\ 2. Hubei Engineering university, Xiaogan, Hubei 432100
}

Keywords: Yuanye; Conceived; Environmental ceramic art; Character

\begin{abstract}
From the embodied jacquard (that is, the design layout) according to analysis from the view of modern environmental ceramic art design, summarizes its main characteristics: its three modes (public, nationality and regionality), similar to the height of the landscape design, and construction of shadow, practical and decoration closely hand in hand, making multiple ways of expressing people unremitting pursuit of material and spiritual double satisfaction.

Modern environmental pottery design is a new term since the reform and opening up, but the history of pottery applied in environmental design is quite long, with the economic and social development and progress, the phenomenon that the ceramic technology being applied in environment design and application is showing the ascendant. The research on its inheritance and innovation is more and more extensive and thorough, but from the "garden metallurgy" artisans to sort out the characteristics of modern environmental art design (ie, the main features), the research papers to make an interpretation research and analysis for him, in order to adapt to and promote the rapid development of environmental pottery design and make a summary have not yet, so from this point of view, the research has the reality of the necessity.
\end{abstract}

\section{Overview of Ji Cheng "Garden Metallurgy" and Modern Environmental Ceramics Design}

"Garden Metallurgy" is a monograph of Chinese ancient garden design, but also the monograph of the first garden art theory in China. It was made by garden builder Ji Cheng, Wujiang County people, Suzhou, Jiangsu Province in the Ming Dynasty, which was written in Ming Chongzhen four years (AD 1631). The book discussed the principles of the construction of the house and the villa, and provided a theoretical framework and a model for the design and construction of the later garden. It reflects the achievements of the ancient Chinese garden and sums up the experience of the garden, an important work of studying ancient garden design .

Modern environmental ceramic design, is using ceramic materials in accordance with the law of the aesthetics to carry out practical and decorative design for the indoor, outdoor, landscape and other large and small environmental space for, to create a livable environment of art design categories. Modern environmental ceramics is not only indoor and outdoor, scenes and other environmental practical and decorative design, but also is the practical and comprehensive environmental design of the combination of "workers" and "art" of the building along with the shape of the ceramic material.

\section{The Common View of "Garden Metallurgy" Artisans and Modern Environmental Design}

(1) Emphasis on the overall design and ideas before the construction and implementation

"Garden metallurgy" written by Ji Cheng is also said nurturing garden, which contains garden design practice and the garden design theory the two parts. As the practical garden design, it must have a set of design-related elements, follow the relevant rules and laws of design itself. "Garden metallurgy" also do this really, it is same to the modern environment design of ceramics, with the first common ground is to focus on the overall concept and design before the construction of the implementation, and attaches great importance to this process, that is, creative design process, it is to ensure that good design works can produce the guarantee, but also make the design like a design, so as to achieve the design of high quality. Today, the CAD-aided design, CMD auxiliary manufacturing and other computer technology are developed, the physical model design from 
traditional heritage is still design of auxiliary means that we are relying on, this emphasis on the design and the idea before the construction of the implementation is particularly valuable and meaningful. Similarly, the design of modern environmental ceramics is also strictly following the design process, from the creative ideas gradually to the specific design, such as model samples or 3DMAX, rhinoceros and other software renderings design, and finally into the entity construction and implementation.

(2) In the overall treatment, we need to grasp design principles of attaching attention to the big place and emphasize on the details of the operation

The garden design and construction in "garden metallurgy" reflects the standard grasp of the big focus, fine to start the operation of the design artisans. First of all, garden construction is divided into "garden say" and "construction theory" two parts, among the two main parts, subdivided, sub-categories describing the phase, base, paving, stone and other specific design and construction methods. At the same time, in order to make the construction and construction easy to be operated, but also detailedly drawing more than two hundred pieces such as making walls, paving, doors and windows and other design patterns or drawings, through such detailed drawings of the drawings, which can be achieved to the creative design to the physical garden of the transformation, to build a garden meeting customer needs.

Modern environmental art design also follow the design process, in the creative design to complete the design drawings, the specific implementation process is to follow the global approach to the decomposition, to the various parts or details to be resolved, and then assembled. So from this point of view, the modern environment of ceramic design and garden design of the two principles and requirements can be described as the same thing, it ensures that the design drawings or creative ideas get a good expression or perfect expression.

(3) In the overall atmosphere, emphasizing the "artistic conception" creation, and through the actual situation, distance and other methods to achieve them

The final effect of "garden metallurgy" artisans in the garden or garden design and construction, or creativity and the original intention, is the pursuit of a realm, that is literati "mood" to create a great, leisure, elegant mood, through the expansion of their own vision, and with the sense of hearing, smell, to enjoy the eyes and ears of all the good things in nature, such as vegetation, flowers, island language, insects, lakes and mountains and four seasons changes and so on.

Modern environmental art design is also the pursuit of "artistic conception" to create, but also the use of entities and void to create the original design of all kinds of related and expected to achieve the artistic effect, gives a meaningful visual enjoyment.

\section{The Differences between "Garden Metallurgy" with Modern Art Design}

(1) One is based on practical and appreciation, other one is as the landscape of public space and decorative design

The design concept of "garden metallurgy" in the practice of landscape is to use a certain area of engineering technology and art means, through the transformation of terrain and landscape, planting trees and flowers, to create a building and layout garden road or artificially open up landscape, combined plant planting and construction of the layout, which constitutes a man-made beauty of the natural environment for people to visit and walk, watch, rest, live with, giving the psychological and spiritual soothing effect of the design of the garden.

Modern environment ceramic design not only have the practical function of the separation of space, but also make practical and decorative design as a split space in different forms to meet people's convenience, as well as inner thinking, spiritual needs. So it treats practical as basis, and mainly create the architectural decoration, ornamental, cultivate sentimental urban public space important form of expression. So the two of them are based on a physical garden-based, one is decorated with landscaping-based, on this basis, the two go to give modeling entities and decoration to appreciate, cultivate spiritual pursuit;

(2) One is pursuit of natural wild and dignified solemn two extremes, other one pursuit of a wider range of aesthetic taste 
"Garden metallurgy" is an integral part of China's splendid ancient culture, but also the crystallization of the wisdom and creativity of the ancient Chinese working people, but because in the history who support or are affordable garden design objects are generally produced, having the right, or leisurely class, so the garden design for the long-term are occupied by the ruling class and dignitaries, wealthy merchants, and relations with the general public is not big, so the pursuit of garden design and art is mainly their philosophy, religion faith, culture and arts and other aspects of comprehensive reflection. These features of the garden design can be seen in the history of the comparison is more clear and thorough. However, after a long history, in the new era of garden design, because the support power is mainly the country, in addition to national strength, another garden design is basically very small, while the national government departments at all levels is making protection of the restoration and reconstruction basically on the original garden, due to respect and protection of the traditional requirements, repair old as old, so the pursuit of these design are basically inheriting the ancient "garden" style and tradition, but on the basis of the original copy or slightly so as to show the historical style of Chinese garden culture.

Modern environmental art design is facing modern people with new ideas and new concepts, its support force in addition to national governments at all levels, there are various types of organizations and private forces to support, so the scope of object it face or enjoy is more broad, and its audience object expansion, so the pursuit of style can not be "invariable change" in a way and style to deal with, to meet the different classes of aesthetics. It embodies the glimpse of the simple pattern, the design of the aesthetics, artificial beauty, the transformation of the aesthetics and the beauty of conquest is an open or highly personalized expression, a majority of people enjoy the "public paradise ", such as the traditional Chinese or Western style expression, and some in Chinese and Western style and other comprehensive way to express, etc., in short, it has the diversified style features of strong visual pleasure, entertainment, embodying the cultural connotation of various cities and historical memory, intellectual education and other functions.

(3) one pursuit of elegant leisurely beauty, other one pursuit of innovation and create beauty

the creative thinking of "garden metallurgy" in the design of the garden, it is designed to reflect the poetic art, so from the aesthetic to the creation of garden mood it is a natural view, freehand, poetic painting to become the dominant position of its garden design, not only imitate the natural landscape, but also set the imitation of the famous places in a garden, the formation of style of a park in the garden, a large garden containing a small one.

The modern environment pottery and the expression of the garden design of Ji Cheng in the way like the twists and turns is different, it is straightforward, because the carrier of the environment pottery - whether it is three entities such as ceramic wall artifacts or artifacts, its size, size or space, generally not too great, in the expression of the decision on its design is directly or sharply to see the intuitive, can not drag the space, so this intuitive expression of the way of the environment pottery with the west garden design has several similar, such as France the regular garden of Paris Versailles, to advocate open, popular neat, the axis of the geometric pattern of symmetry, through artificial beauty to show the control and transformation of nature, show "Man-made" force. In the expression of feelings, people with modern ideas in the expression of the design of the environment are more straightforward, revealed, not subtle than the garden of the ancient times, but the truth exposed, thoroughly and brightly express their emotions, showing a basic opposition with the pastin fact, the past "gentle and subtle" -based supplement, opposition or negation enriched the expression of environmental design emotions.

\section{Conclusion}

In view of the above summary, by standing in the "garden metallurgy" artisan point of view overlooking the modern environment ceramic design, we can see that the garden design is not only the design of the garden, large-scale comprehensive design; modern environmental ceramics is not only public, national and regional artistic characteristics, but also on the indoor and outdoor, landscape, scenes and other environmental decoration design, and the building with the shape of the small comprehensive design, they have a history of continuity and variable upgrade character, that is, inheritance and development, advancing with the times: First of all, the modern environment of 
ceramic design and landscape design are in the ancient solid foundation for the accumulation of design and continue to develop, the difference is that the park tend to multi-points and design details, the modern environment pottery go forwards to the depth and expansion, the garden artisans give the environmental pottery useful reference, environmental ceramic design made a vivid interpretation, play and supplement on the view of the garden; contemporary garden design by land restrictions, economic factors, style features, political requirements (such as anti-corruption, saving the requirements can not be overhauled building buildings) and many other factors, however, the direct and flexible characteristics of environmental pottery have determined that it has the possibility of rapid development in social life, and presents is in the ascendant.

Secondly, the garden craftsmen as a traditional garden design point of view, ideas, technical methods, aesthetic pursuit, cultural connotation of the comprehensive extraction and summary of the future of the garden and the modern building environment ceramics, they have provided a useful reference. Modern environment pottery as a combination of ancient pottery and modern environment design of the two continuation and extension of the design not only refer to the design of the city of art, but also into the modern concept, ideal and reflect the new era of science, technology and the use of methods, it is in the new era of further development is beneficial, so a variety of ways by taking the ancient to use today, advancing with the times, learn from each other for people to meet the spirit of pleasure, create a better living environment, and even promote economic and cultural development to offer new possibilities. In this way, from this perspective of the "garden metallurgy" artisan to do the study of the characteristics of modern environmental pottery also have practical significance.

\section{Reference}

[1] (Ming)JI Cheng Compile, Chen Zhi note.YuanYe [M]. China building industry press. 1988 edition:88.

[2] Feng Xianming. History of Chinese ceramics [M]. Cultural relics publishing house. 1982. Print. In December 2006(12):418.

[3] Chen Jun. Portrait interpretation of Chinese dream ,Jiulonghu painted chapter [J]. Journal of ceramics science and art. 2017 (6):12.

[4] yong-ping wu. Environmental ceramic art design [J]. Decoration. 2003(12):71.

[5] He Bingqin. Modern environmental ceramic art design [J]. Journal of China ceramics.2007 (12):16. 